\title{
Measuring Spirituality and Religiosity in Clinical Settings: A Scoping Review of Available Instruments
}

\author{
Philip Austin 1,*, Jessica Macdonald ${ }^{2}$ and Roderick MacLeod 2,3 \\ 1 Department of Pain Management, HammondCare, Greenwich 2065, Australia \\ 2 Department of Palliative Care, HammondCare, Greenwich 2065, Australia; jessica.macdonald84@gmail.com \\ 3 Medical School-Northern, The University of Sydney, St Leonard's 2065, Australia; \\ rmacleod@hammond.com.au \\ * Correspondence: paustin@hammond.com.au
}

Received: 22 February 2018; Accepted: 28 February 2018; Published: 4 March 2018

\begin{abstract}
Aims: Numerous measures exist that assess dimensions of spirituality and religiosity in health, theological and social settings. In this review, we aim to identify and evaluate measures assessing factors relating to spirituality and religiosity in clinical settings. Methods: A systematic literature search was conducted using PubMed, EMBASE and PsycINFO databases with search terms relating to spirituality, religiosity that also included well-being, needs, distress and beliefs used in self-reporting and clinician-administered measures. Only articles relating to the validation and subsequent administration of measures used in clinical settings were eligible for review. Results: Of 75 measures selected for initial screening, 25 had been validated and used in clinical settings and were reviewed for this study. Most measures were validated in oncological and palliative care settings where the Functional Assessment of Chronic Illness Therapy Spiritual Well-being (FACIT-Sp12) and the World Health Organization Quality of Life Spiritual, Religious and Personal Beliefs (WHOQOL-SRPB) were most validated and frequently used. Only six measures were found that assessed spiritual distress and/or the needs of which only two had been investigated more than twice. Two measures assessing spirituality and religious beliefs in healthcare staff were also reviewed. Conclusions: This review provides a current summary of measures evaluating several dimensions of spirituality and religiosity used in clinical settings. Currently there is a lack of reliable measures evaluating spiritual needs and distress.
\end{abstract}

Keywords: spirituality; spiritual well-being; religiosity; religious beliefs; clinical setting; evaluation; measurement; scoping review

\section{Introduction}

Recently, associations between spirituality, religion, health and quality of life have been investigated in many areas of healthcare including general medicine, psychology and nursing. Spirituality and religiosity are intricate constructs that describe peoples' fundamental beliefs about existence that form attitudes and behavior across many different cultures (Baumsteiger and Chenneville 2015). Generally, studies show that people with higher levels of spirituality and religiosity have lower levels of depression and anxiety, improved quality of life, a higher pain tolerance and a lower prevalence of chronic disease (Lucchetti et al. 2013; Koenig 2009; Koenig 2012). Additionally, spiritual and religious people show strong humanitarian attitudes while also interacting in large social networks (Becker and Dhingra 2001). Although spirituality and religion are closely related, definitions differ and as such for the purposes of measurement can be considered as two separate constructs. Religiosity is often defined as the adherence to beliefs, doctrines, ethics, rituals, texts and practices associated with a higher power either alone or among organized groups (Hood and Spilka 2003). Alternatively, spirituality is defined as a set of inner experiences and feelings through 
which a person inwardly seeks meaning and purpose as well as relationships to self, family, others, society, nature and the significant or sacred (Baumsteiger and Chenneville 2015; Austin et al. 2017). Although there is some overlap in definitions where many believe spirituality to encompass religious practices, studies investigating opinion suggest both religious leaders and laypeople consider religion as beliefs based on rules associated with organized practice whereas spirituality is more personal, internal and independent of communal relationships (Hyman and Handal 2006; Zimmer et al. 2016).

Given these definitions, it is not surprising that religion and spirituality have been identified as important coping resources for patients during times of chronic and terminal illness. Here, patients often think about their life, its meaning and the experience of the disease process especially in times of anxiety, pain, loneliness and deprivation, all which challenge ideals and beliefs (Austin et al. 2017). Recent studies show differences in self-reported spirituality and religiosity towards these negative emotional experiences. For example, MacLeod and colleagues show that strong religious beliefs are associated with high levels of anxiety in people thinking about their own death compared to those with strong spiritual beliefs who show significantly lower levels of anxiety about their own death (MacLeod et al. 2017). Cotton and coworkers also show differences in the meaning of religion and spirituality when characterizing these belief systems in a large and diverse sample of HIV/AIDS patients. Here they found that those patients used their religion/spirituality to cope with difficult situations such as guilt, shame and bereavement associated with the disease that in turn were associated with improvements in life satisfaction and self-rated health (Cotton et al. 2006). Given these findings, it is important to be aware the effect of potentially life-threatening diagnoses can have on a person's ability to cope with religious and spiritual issues during clinical meetings. Thus, health professionals must have the emotional, social and spiritual resources to both evaluate and carry out their work both individually and as part of a multi-disciplinary team.

However, to offer spiritual and religious interventions, evidence-based, valid assessments or measures must be available in clinical settings. Additionally, definitions of religion and more-so spirituality in the context of healthcare vary greatly where in simplistic terms they describe spirituality as good and religion as bad. Such definitions overlook the potentially helpful and harmful effects of religious and spiritual interventions (Hill and Pargament 2003). Moreover, it is also unknown if and what measures are applicable in clinical settings to assess levels of religious and/or spiritual distress and thus appropriate intervention (Puchalski et al. 2009). Although several authors have reviewed the concepts and implications of religion and spirituality in clinical and healthcare research settings (Monod et al. 2011), none have addressed the range, classification or the validity of available measures to reliably assess these constructs. In a systematic review, Monod and colleagues identified 35 measures evaluating general spirituality, spiritual well-being and spiritual coping. However, $35 \%$ of selected measures had only been studied within clinical settings with the remaining being investigated in social, theological and psychiatric settings. Thus, the purpose of this study is to provide a scoping review of measures currently used to identify and evaluate levels of spirituality, spiritual well-being, spiritual distress and religion in clinical settings.

\section{Methods}

Our scoping review was conducted using a framework defined by Colquhoun and colleagues as "a form of knowledge synthesis that addresses an exploratory research question aimed at mapping key concepts, types of evidence and gaps in research related to a defined area or field by systematically searching, selecting and synthesizing existing knowledge (Colquhoun et al. 2014). The research question for this review is "Do current instruments identify and evaluate levels of spirituality, religiosity spiritual needs and distress in clinical settings?" PubMed, EMBASE and PsycINFO databases were searched in December 2017 (Table 1). Eligibility criteria required publications to (a) relate to instrument development and validation and use thereafter; (b) that instruments were applicable to clinical settings and (c) Acceptance of English and non-English articles. Due to the volume of articles describing the use of self-reporting measures relating to our specific areas of interest, and the time-scale allowed for 
searching and evaluating located articles, as recommended by Mateen and colleagues we screened for keywords in titles of publications (Mateen et al. 2013). Once measures were selected, we modified our search protocols to search both titles and abstract using the name of the measure to locate and verify the number of investigations within clinical settings.

Table 1. Keywords used in the location of articles investigating the use of measures evaluating spirituality, Spiritual well-being, spiritual distress, religiosity and religious beliefs.

\begin{tabular}{|c|c|c|}
\hline PubMed & EMBASE & PsycINFO \\
\hline $\begin{array}{l}\text { Keywords limits } \\
\text { - } \quad \text { Advanced search-“Title" } \\
\text { - } \quad \text { Boolean search-“AND" }\end{array}$ & $\begin{array}{l}\text { Keywords limits } \\
\text { - } \quad \text { Multifield search-“Title" } \\
\text { - } \quad \text { Boolean search-“"AND” } \\
\text { - } \quad \text { Exclude Medline journals }\end{array}$ & $\begin{array}{l}\text { Keyword limits } \\
\text { - } \quad \text { Multifield search-“Title" } \\
\text { - } \quad \text { Boolean search-“AND" } \\
\text { - } \quad \text { Peer-review only }\end{array}$ \\
\hline
\end{tabular}

AND

Keywords

Spirituality

Spiritual well-being

Spiritual distress

Spiritual needs

Religiosity

Religious beliefs

\section{Keywords}

Scale

Measure

Instrument

Index

Inventory

Questionnaire

\section{Results}

Using the above search protocols, we located 386 articles relating to the use and validation of measures evaluating spirituality and religiosity/religious beliefs in a variety of settings. We then selected articles for initial screening that related to the development, validation and subsequent use of self-reporting measures specific to spirituality, spiritual well-being, spiritual distress, spiritual needs, religiosity and religious beliefs (n-156). After removing all duplicates, 121 articles were selected for further evaluation. Of remaining articles, 72 investigated spirituality and religiosity in clinical settings, 16 in psychiatric clinical settings and 33 in social settings (Figure 1). Overall, we identified 25 measures used in a variety of clinical settings and 30 measures used in psychiatric, theological and social settings. For the purposes of this study, we shall briefly review measure of spirituality, spiritual well-being, religiosity, religious beliefs, spiritual distress and spiritual needs used in clinical settings (Tables 2 and 3).

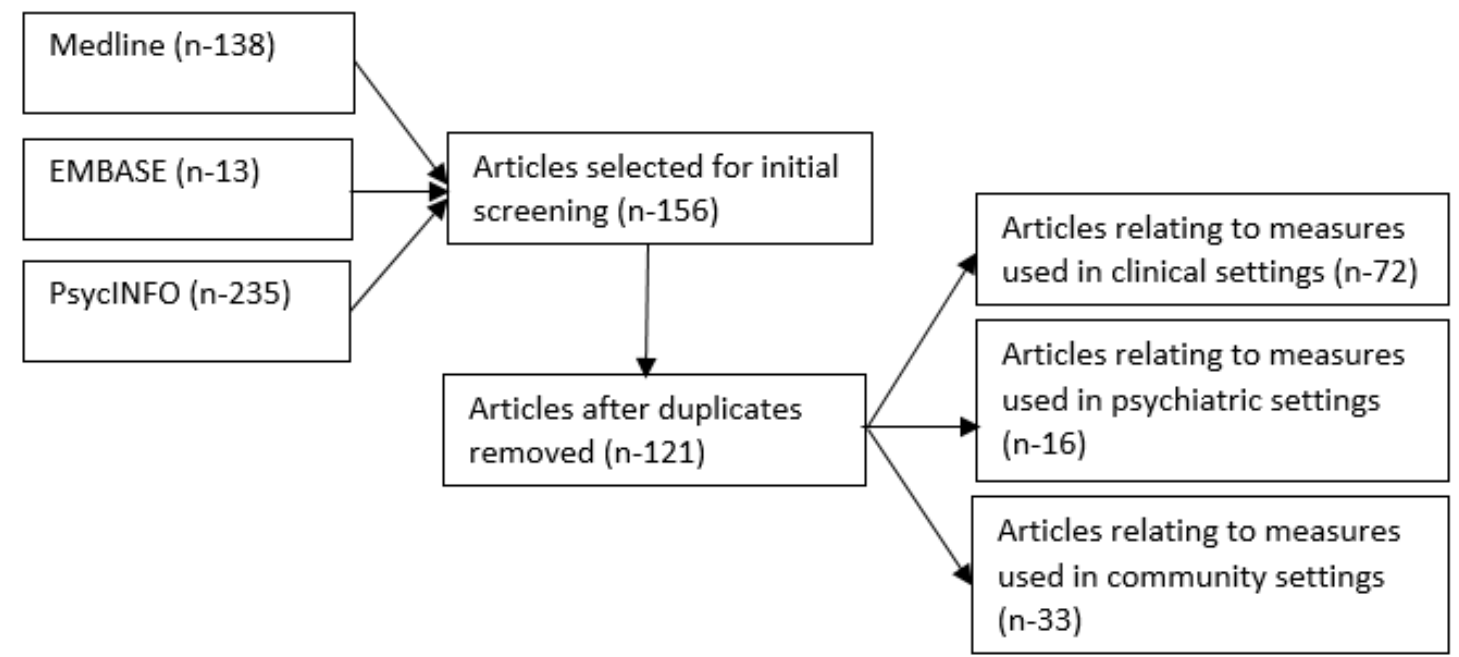

Figure 1. Search flow chart showing total numbers of articles located and screen for review. 
Table 2. Spirituality, spiritual well-being, religiosity and religious beliefs measures used in clinical settings.

\begin{tabular}{|c|c|c|c|c|}
\hline Authors & Instrument Name & Sample Size & Type of Study & Findings \\
\hline $\begin{array}{l}\text { Daaleman and Frey } \\
\qquad 2004\end{array}$ & $\begin{array}{l}\text { The Spirituality Index of } \\
\text { Well-Being (SIWB) }\end{array}$ & $\begin{array}{l}523 \text { outpatients from family } \\
\text { practice }\end{array}$ & $\begin{array}{l}\text { Factor } \\
\text { analysis/test-retest } \\
\text { reliability }\end{array}$ & $\begin{array}{l}\text { Correlations with quality of life, } \\
\text { health status and depression }\end{array}$ \\
\hline Kaczorowski 1989 & $\begin{array}{l}\text { The Spiritual Well-Being } \\
\text { Scale }\end{array}$ & 114 cancer patients & Cross-sectional & $\begin{array}{c}\text { Inverse correlations between low } \\
\text { levels of spiritual well-being and } \\
\text { high levels of anxiety }\end{array}$ \\
\hline $\begin{array}{l}\text { Peterman et al. } \\
\quad 2014\end{array}$ & $\begin{array}{l}\text { The Functional Assessment } \\
\text { of Chronic Illness } \\
\text { Therapy-Spiritual } \\
\text { Well-Being (FACIT-Sp) }\end{array}$ & $\begin{array}{l}2923 \text { cancer and HIV } \\
\text { patients }\end{array}$ & $\begin{array}{l}\text { Factor analysis and } \\
\text { Observational }\end{array}$ & $\begin{array}{l}\text { Strong internal consistency and } \\
\text { moderate to strong correlations } \\
\text { between FACIT-Sp and quality of } \\
\text { life, especially meaning and peace }\end{array}$ \\
\hline $\begin{array}{l}\text { De Camargos et al. } \\
2015\end{array}$ & WHOQOL-SRPB & $\begin{array}{l}525 \text { oncology patients / } 525 \\
\text { health professionals }\end{array}$ & Cross-sectional & $\begin{array}{l}\text { Daily use of spiritual and } \\
\text { religious resources positively } \\
\text { effects patient perceptions of QOL }\end{array}$ \\
\hline $\begin{array}{l}\text { Bussing and } \\
\text { Koenig } 2008\end{array}$ & BENEFIT Scale & 229 chronic pain patients & $\begin{array}{l}\text { Reliability and } \\
\text { validation }\end{array}$ & $\begin{array}{c}\text { The BENEFIT scale correlates } \\
\text { uniquely with spiritual and } \\
\text { religious attitudes in clinical } \\
\text { studies }\end{array}$ \\
\hline Vivat et al. 2017 & EORTIC QLC-SWB32 & $\begin{array}{l}451 \text { palliative care patients } \\
\text { from } 14 \text { countries }\end{array}$ & Validation & $\begin{array}{l}\text { The EORTIC QLC-SWB32 } \\
\text { measures distinct aspects of QOL }\end{array}$ \\
\hline Bussing et al. 2016 & SpREUK & 275 cancer patients & $\begin{array}{l}\text { Factor analysis and } \\
\text { reliability }\end{array}$ & $\begin{array}{l}\text { A valid measure of important } \\
\text { aspects of spirituality and } \\
\text { religious attitudes }\end{array}$ \\
\hline Kreitzer et al. 2009 & Brief Serenity Scale & $\begin{array}{l}87 \text { post solid organ } \\
\text { transplant patients }\end{array}$ & $\begin{array}{l}\text { Factor analysis and } \\
\text { reliability }\end{array}$ & $\begin{array}{l}\text { The Brief Serenity Scale captures } \\
\text { dimensions of spirituality, a state } \\
\text { of acceptance, inner haven and } \\
\text { trust that is distinct from other } \\
\text { spirituality instruments }\end{array}$ \\
\hline Delaney 2005 & The Spirituality Scale & $\begin{array}{l}226 \text { patients with chronic } \\
\text { illness }\end{array}$ & $\begin{array}{l}\text { Reliability and } \\
\text { validation }\end{array}$ & $\begin{array}{l}\text { The Spirituality Scale provides a } \\
\text { 3-factor framework } \\
\text { (self-discovery, relationships and } \\
\text { eco-awareness) that help with } \\
\text { nursing care }\end{array}$ \\
\hline Ironson et al. 2002 & $\begin{array}{c}\text { The Ironson-Woods } \\
\text { Spirituality/Religiosity } \\
\text { Index }\end{array}$ & $\begin{array}{l}279 \text { HIV positive patients } \\
\text { and long-term AIDS } \\
\text { survivors }\end{array}$ & $\begin{array}{l}\text { Reliability and } \\
\text { validation }\end{array}$ & $\begin{array}{l}\text { Long-term survival related to } \\
\text { frequency of positive prayer and } \\
\text { non-judgmental attitudes }\end{array}$ \\
\hline $\begin{array}{l}\text { Johnstone et al. } \\
\qquad 2016\end{array}$ & $\begin{array}{l}\text { The Brief Multidimensional } \\
\text { Measure of } \\
\text { Religiousness/Spirituality } \\
\text { (BMMRS) }\end{array}$ & $\begin{array}{l}109 \text { traumatic brain injury } \\
\text { patients }\end{array}$ & Factor analysis & $\begin{array}{l}\text { The BMMRS is a valid measure of } \\
\text { emotional connectedness with } \\
\text { higher power and social support } \\
\text { among different spiritual and } \\
\text { religious variables }\end{array}$ \\
\hline Hatch et al. 1998 & $\begin{array}{l}\text { The Spiritual Involvement } \\
\text { and Beliefs Scale }\end{array}$ & $\begin{array}{l}50 \text { primary care patients and } \\
23 \text { family practice educators }\end{array}$ & Factor analysis & $\begin{array}{l}\text { The SIBS shows that included } \\
\text { terms avoid cultural and religious } \\
\text { bias in both beliefs and actions }\end{array}$ \\
\hline $\begin{array}{l}\text { McBride et al. } \\
\text { 1998b }\end{array}$ & $\begin{array}{c}\text { The Brief Pictorial } \\
\text { Instrument for Assessing } \\
\text { Spirituality }\end{array}$ & 442 family practice patients & $\begin{array}{l}\text { Reliability and } \\
\text { validation }\end{array}$ & $\begin{array}{l}\text { The pictorial instrument provides } \\
\text { a quick assessment of intrinsic } \\
\text { spirituality correlating with other } \\
\text { spirituality measures }\end{array}$ \\
\hline $\begin{array}{l}\text { VandeCreek et al. } \\
1995\end{array}$ & $\begin{array}{l}\text { The Index of Core Spiritual } \\
\text { Experience (INSPIRIT) }\end{array}$ & $\begin{array}{l}371 \text { medical and surgical } \\
\text { outpatients }\end{array}$ & $\begin{array}{l}\text { Reliability and } \\
\text { validation }\end{array}$ & $\begin{array}{l}\text { INSPIRIT assessment reflects } \\
\text { intrinsic religiosity and } \\
\text { spirituality }\end{array}$ \\
\hline Kimura et al. 2012 & $\begin{array}{l}\text { The Daily Spiritual } \\
\text { Experience Scale DSES) }\end{array}$ & 179 surgical patients & $\begin{array}{l}\text { Cultural } \\
\text { adaptation and } \\
\text { validation }\end{array}$ & $\begin{array}{l}\text { The DSES shows evidence of } \\
\text { reliability and validity in } \\
\text { assessing spiritual experiences } \\
\text { among hospitalized patients }\end{array}$ \\
\hline $\begin{array}{l}\text { Gherghina et al. } \\
2014\end{array}$ & $\begin{array}{l}\text { The Spiritual Distress } \\
\text { Assessment Tool (SDAT) }\end{array}$ & $\begin{array}{l}72 \text { elderly erioperative } \\
\text { patients }\end{array}$ & Validation & $\begin{array}{l}\text { The SDAT appears to be a reliable } \\
\text { and valid instrument to assess } \\
\text { spiritual distress in elderly } \\
\text { hospitalized patients }\end{array}$ \\
\hline Chiang et al. 2017 & The Religious Belief Scale & 619 clinical nurses & Factor analysis & $\begin{array}{l}\text { A reliable and valid scale for } \\
\text { measuring religious beliefs of } \\
\text { nurses }\end{array}$ \\
\hline $\begin{array}{l}\text { McSherry et al. } \\
2002\end{array}$ & $\begin{array}{l}\text { The Spirituality and } \\
\text { Spiritual Care Rating Scale }\end{array}$ & 549 ward-based nurses & Factor analysis & $\begin{array}{l}\text { Factors identified: spirituality, } \\
\text { spiritual care, religiosity and } \\
\text { personal care }\end{array}$ \\
\hline $\begin{array}{l}\text { Kouloulias et al. } \\
\qquad 2017\end{array}$ & The QRFPC-25 & $\begin{array}{l}156 \text { cancer patients } \\
\text { undergoing radiotherapy }\end{array}$ & $\begin{array}{l}\text { Reliability and } \\
\text { validation }\end{array}$ & $\begin{array}{l}\text { A reliable and valid gauge for } \\
\text { assessment of religiosity in cancer } \\
\text { patients }\end{array}$ \\
\hline
\end{tabular}


Table 3. Spiritual needs and spiritual distress measures used in clinical settings.

\begin{tabular}{lllll}
\hline Bussing et al. 2018 & $\begin{array}{l}\text { Spiritual Needs } \\
\text { Questionnaire }\end{array}$ & $\begin{array}{l}\text { 627 chronic disease patients } \\
940 \text { elderly ill patients } \\
1468 \text { healthy adults }\end{array}$ & $\begin{array}{l}\text { Factor analysis and } \\
\text { reliability }\end{array}$ & $\begin{array}{l}\text { This large study provides } \\
\text { evidence for a cultural and } \\
\text { religious sensitive measure } \\
\text { that evaluates peoples } \\
\text { spiritual needs }\end{array}$ \\
\hline Ku et al. 2010 & $\begin{array}{l}\text { The Spiritual } \\
\text { Distress Scale } \\
\text { (SDS) }\end{array}$ & 85 cancer patients & Factor analysis & $\begin{array}{l}\text { The SDS is both reliable and } \\
\text { valid in assessing patients in } \\
\text { oncological settings and aids } \\
\text { nurses in the assessment of } \\
\text { spiritual distress }\end{array}$ \\
\hline Astrow et al. 2015 & $\begin{array}{l}\text { The Spiritual } \\
\text { Needs Assessment } \\
\text { for Patients (SNAP) }\end{array}$ & $\begin{array}{l}727 \text { haematology and cancer } \\
\text { patients }\end{array}$ & $\begin{array}{l}\text { Observational and } \\
\text { validation }\end{array}$ & $\begin{array}{l}\text { SNAP is reliable and valid in } \\
\text { measuring spiritual needs in } \\
\text { patients from different } \\
\text { cultural and religious } \\
\text { backgrounds }\end{array}$ \\
\hline $\begin{array}{l}\text { Buck and McMillan } \\
2012\end{array}$ & $\begin{array}{l}\text { The Spiritual } \\
\text { Needs Inventory } \\
\text { (SNI) }\end{array}$ & 410 cancer patient caregivers & $\begin{array}{l}\text { Reliability and } \\
\text { Validity }\end{array}$ & $\begin{array}{l}\text { Use of the SNI in hospice } \\
\text { caregivers can aid nurses in } \\
\text { the identification of patients' } \\
\text { spiritual needs }\end{array}$ \\
\hline Monod et al. 2010 & $\begin{array}{l}\text { The Spiritual } \\
\text { Needs Assessment } \\
\text { Tool (SDAT) }\end{array}$ & $\begin{array}{l}203 \text { Geriatric rehabilitation } \\
\text { patients }\end{array}$ & $\begin{array}{l}\text { Reliability and } \\
\text { Validity }\end{array}$ & $\begin{array}{l}\text { The SDAT shows adequate } \\
\text { reliability and validity in } \\
\text { assessing levels of spiritual } \\
\text { distress }\end{array}$ \\
\hline $\begin{array}{l}\text { Fischbeck et al. } \\
2013\end{array}$ & $\begin{array}{l}\text { The Advanced } \\
\text { Cancer Patients' } \\
\text { Distress Scale }\end{array}$ & $\begin{array}{l}168 \text { advanced cancer } \\
\text { patients }\end{array}$ & Factor analysis & $\begin{array}{l}\text { Initially shown to be reliable } \\
\text { in identifying patients } \\
\text { spiritual needs }\end{array}$ \\
\hline
\end{tabular}

\section{Self-Reporting Measures (Spiritual and Religious Well-Being)}

Nearly all measures were validated in oncological and palliative care settings. The instrument validated in the largest clinical population was the FACIT-Sp12. This 12-item measure consists of three factors, those being meaning, peace and faith and has been designed to be used specifically in healthcare settings in people with chronic and life-threatening conditions. The FACIT-Sp12 was initially validated in a population of 1617 cancer patients to determine structure and initial validity of the questionnaire and second in 131 cancer patients to establish reliability (Peterman et al. 2002). More recently, in a larger study, the FACIT-Sp12 has also been used to examine spiritual well-being in nearly 9000 cancer survivors across the United States (Munoz et al. 201). Overall, the FACIT-Sp12 one of the most commonly used is shown to be a brief, reliable and probably the most valid measure of spirituality in quality of life in both religious and nonreligious people.

Although the WHOQOL-SRPB has been well-validated in social settings across 18 different countries (WHOQOL SRPB Group 2006), it has only recently been validated and used regularly within clinical settings. Here we found one study where Rusa and colleagues evaluated both the WHOQOL-SRPB and its short-form version; the WHOQOL-SRPB BREF in 110 chronic kidney disease patients undergoing hemodialysis (Rusa et al. 2014). The authors found that most participants showed high spirituality, religion and personal belief scores, especially in those where their disease was well-controlled. Patients whose disease hemodialysis was not well controlled showed lower scores and, thus less able to cope with chronic kidney failure.

The Spiritual Well-Being Scale (SWBS) was initially validated among social (Genia 2001) and psychiatric settings (Fernander et al. 2004). However, this measure is now being used within clinical settings and has been translated into several different languages such as Persian and Thai. Recently, for example, Ghodsbin and coworkers used the SWBS to show improvements in spiritual well-being in 90 coronary artery disease patients during a positive thinking training compared to a control group (Ghodsbin et al. 2015).

The Spirituality Index of Well-Being (SIWB) is also considered one of the more valid measures for the assessment of patients' current spiritual state (Monod et al. 2011). This measure is a 20-item instrument consists of two subscales relating to religious and existential well-being (Daaleman and Frey 2004). However, although this measure was initially validated in 509 adult 
outpatients at 10 city primary care clinics, it is not widely used. The SIWB shows associations in health and well-being constructs across primary care and geriatric outpatient settings (Daaleman et al. 2002) and has recently been translated into Chinese (Wu et al. 2017).

The 26-item Spiritual Involvement and Beliefs Scale (SIBS) was initially validated in primary care settings to assess levels of spiritual beliefs and practice (Hatch et al. 1998). However, the SIBS has been mostly been used in palliative care settings. Here, for example in the same cohort of 82 cancer patients, Mystakidou and colleagues produced four studies investigating relationships between spirituality and mood disorders (Mystakidou et al. 2007), predictors of spirituality in advanced cancer (Mystakidou et al. 2006, 2008a) and at the end of life (Mystakidou et al. 2008b).

\section{Self-Reporting Measures (Spiritual Needs and Distress)}

Our search protocols show The Spiritual Needs Questionnaire (SpNQ) to be the most widely used measure assessing patients' spiritual needs. Büssing and colleagues developed this measure in a heterogeneous sample of 210 German patients with chronic pain conditions and cancer (Büssing et al. 2010). However, at the time of writing our review, Büssing and colleagues further published an article increasing the validity of this measure by examining the structure of the SpNQ in a large sample of ill and healthy younger and elderly adults (n-2095) (Büssing et al. 2018). The SpNQ has also been translated into several languages including Chinese (Bussing et al. 2013a) and Persian (Moeini et al. 2018).

The Spiritual Distress Scale was the only self-reporting measure we located evaluating levels of spiritual distress in clinical settings. Originally developed in Chinese by $\mathrm{Ku}$ and colleagues in 2010 (Ku et al. 2010), it has since been translated and validated into Portuguese (Simao et al. 2016). Although only two studies have used this questionnaire, both sets of authors suggest that an internationally validated self-reporting measure assessing spiritual distress is needed, especially in the recognition of this phenomenon in clinical practice.

The Spiritual Needs Assessment for Patients (SNAP) is a 23-item instrument with domains assessing psychosocial, spiritual and religious needs. Here Sharma and colleagues initially validated SNAP in 47 ambulatory cancer patients from many different religious and cultural backgrounds and shown to be a valid measure of spiritual needs diverse patient populations (Sharma et al. 2012). Recently, SNAP has been translated into Chinese (Astrow et al. 2012) and Portuguese (De Araujo Toloi et al. 2016a, 2016b).

Several other spirituality/spiritual well-being/spiritual needs/spiritual distress measures have also been used within clinical setting, but only on three or less occasions. These include:

- The BENEFIT Through spirituality/religiosity scale (chronic diseases and spinal cord injury) (Bussing and Koenig 2008; Xue et al. 2016),

- The Brief Pictorial Instrument for Assessing Spirituality (primary care patients) (McBride et al. 1998b),

- The Spirituality Scale (cardiovascular disease and chronic disease patients) (Delaney 2005; Delaney et al. 2011),

- The Index of Core Spiritual Experience (primary care and hospital outpatients) (McBride et al. 1998a; VandeCreek et al. 1995),

- The Ironson-Wood Spirituality/Religiosity Index (HIV and chronic heart failure patients) (Bekelman et al. 2010; Ironson et al. 2002; Mistretta et al. 2017)

- The Brief Multidimensional Measure of Religion and Spirituality (hospital inpatients) (Curcio et al. 2015; Johnstone et al. 2009)

- $\quad$ The Daily Spiritual Experience Scale (surgical, hospice care and HIV patients) (Kimura et al. 2012; Oji et al. 2017; Steinhauser et al. 2008)

- The Brief Serenity Scale (post-transplant patients (Kreitzer et al. 2009)

- The Spiritual Needs Inventory (Hermann 2006; Buck and McMillan 2012)

- The Spiritual Distress Assessment Tool (SDAT) (Monod et al. 2010, 2012a) 
- The Advance Cancer Patients' Distress Scale (Fischbeck et al. 2013)

- The Spiritual Care Competence Scale (Van Leeuwen et al. 2009)

Very recently, just before the application of our search protocols, two spirituality/religiosity measures gained validation, both in cancer care. First the QRFPC25, a measure of religiosity and spirituality was validated and shown to be reliable in 156 people with neoplastic disease (Kouloulias et al. 2017). In a larger study, the European Organization for Research and Treatment of Cancer Quality of Life Group Spiritual Well-being-32 (EORTC QLQ-SWB32) was validated in 451 palliative care patients from 14 countries (Vivat et al. 2017).

\section{Clinician-Administered Measures}

Monod and colleagues developed an a spiritual distress assessment tool (SDAT) designed to evaluate spiritual distress in hospitalized older patients using the hypothesis that the greater the degree to which spiritual needs are not met, the greater the level of spiritual distress (Monod et al. 2012b). This measure has four factors, those being meaning (orientation in life), transcendence (relationships with an external foundation), values (determination of goodness and trueness) and psycho-social identity (patient's environment). This clinician administered measure has so far showed to be reliable and valid in both hospital rehabilitation and perioperative hospital settings (Monod et al. 2012b; Gherghina et al. 2014).

\section{Self-Reporting Tools Assessing Healthcare Staff Understanding of Spirituality and Spiritual Care}

We located two measures that establish how people working in health care perceive spiritualty and spiritual care. The Spirituality and Spiritual Care Rating Scale (SSCRS) was developed by McSherry and colleagues to evaluate how nurses perceive spirituality and spiritual care (McSherry et al. 2002). However, this measure has now been translated into several languages (Fallahi Khoshknab et al. 2010; Wu and Lin 2011) and has also been evaluated amongst clinicians, physiotherapists and ancillary workers who have regular contact with patients (Austin et al. 2017). The second measure was validated at the time of writing up this review. Here, the Religious Belief Scale was developed to assess religious beliefs of nurses in order to determine their competence in providing spiritual care to patients. Exploratory factor analysis showed a 17-item scale with four factors: religious effects, divine, religious query and religious stress and was provisionally reliable and valid in measuring religious beliefs in Taiwanese nurses (Chiang et al. 2017).

\section{Discussion}

This scoping review identified 25 measures used to evaluate levels of spirituality, spiritual well-being, spiritual distress, spiritual needs, religiosity and religious beliefs in clinical settings. This review aimed to continue the earlier work of Monod and colleagues (Monod et al. 2011) in identifying more recently validated measures, while also refining the location of measures to those specifically validated and used in clinical settings. The latter aim of this review is relevant as many more (n-30) spiritual and religious measures were located but were validated and applied in psychiatric, theological and social settings and thus it is not known if they are reliable or valid in clinical settings.

Nearly all measures assess patients' current spiritual state or current levels of religiosity, the most widely utilized being the FACIT-Sp 12, the WHOQOL-SRPB, the SIWB and more recently, the EORTC QLQ-SWB32. However, from our results, of the 25 accepted measures, only six assess spiritual needs or distress, where only two have been applied in clinical studies twice or more, those being the Spiritual Needs Questionnaire (Büssing et al. 2010) and the Spiritual Distress Scale (Ku et al. 2010). These findings raise important questions as to the relevance of measures assessing current levels of spirituality/religiosity and the relevance of outcomes determined as a result. Puchalski partially answers these questions in her paper describing the role of spirituality in health care (Puchalski 2001). Here, she describes how spirituality is shown to reduce mortality, aids in the ability to cope with 
illness, pain and life stresses, while also helping to boost recovery from illness and surgery. However, probably the most important statement from her article relates to the importance of understanding patients' spirituality in relation to whole patient care and subsequent health care decisions.

Although, these observations help to gain insight toward correlations between levels of spiritual and religious well-being and the ability to cope and understand their illness from a spiritual/religious perspective, most measures do not assess spiritual needs and levels of spiritual distress. Our observations are similar to Monod and colleagues who rightly suggest that an absence of spiritual well-being is unlikely to equate to a state of spiritual distress (Monod et al. 2011). Furthermore, we found no clinician-administered measures evaluating behaviors associated with spiritual distress. This is also an important finding as although several measure exist evaluating healthcare professionals' understanding of spirituality and spiritual care (Chiang et al. 2017; McSherry et al. 2002), none contain items describing behavior associated with spiritual needs and distress. This deficit was highlighted by Highfield and Carson who found that nurses recognized only five of 31 behaviors, where four of the five contained direct references to God. More recently, Austin and colleagues in a study investigating the ability of clinical and non-clinical staff to recognize patients' spiritual needs showed that although participants were able to recognize written examples of spiritual needs, the majority felt unable to neither recognize nor deal with such needs (Austin et al. 2016, 2017). Such findings suggest that although acquiring information on different areas of spirituality and religiousness in clinical settings is useful, the practical application of this information remains unclear. Thus, as suggested by several authors, in order to make best use of these data concerning effective patient care, spiritual care training is required for both health care staff who administer such measures and staff who have regular contact with patients (Cetinkaya et al. 2013; Balboni et al. 2013; Rasinski et al. 2011).

Interestingly, several measures have recently been developed that examine more specific forms of spiritual distress that may be beneficial for application in clinical settings. Here, constructs such as "spiritual struggle" developed by Exline and colleagues (Exline et al. 2014), a form of inner crisis known as "spiritual dryness" conceived and developed by Büssing and colleagues (Büssing et al. 2013b) and Koenig's "moral injury" (Koenig et al. 2017) have been validated in a number of social setting but may also have relevance in clinical settings when attempting to more accurately identify specific forms of spiritual distress such as burnout and inner peace needs.

Our review, like that of Monod and colleagues in 2011 shows that although there is an abundance of available spiritual and religious measures, there is inadequate data on the psychometric properties for most. This is due mainly to the lack of test-retest reliability and subsequently, predictive validity due to the seldom use of many questionnaires. Additionally, sample size in many validation and factor analysis studies were small, thus lowering the statistical power and the true outcome of these measures. Moreover, most measures evaluate a combination of both spiritual and religious factors while only one measure uniquely assessed religiosity (Chiang et al. 2017). Given the differences in definition and significant differences in attitudes between people who are spiritual compared to those who are religious, we suggest the development of novel religious measures or the validation of those previously used in psychiatric, theological and social settings in clinical settings are required.

Our scoping review had two limitations. First, our search protocols were limited to multiple field searching of keywords in titles only using three databases. Before committing to these search methods, we validated our approach by following the work of Mateen and colleagues who show a titles-only approach to be an efficient method for screening articles in a systematic review (Mateen et al. 2013). However, we, like Mateen and colleagues found that although there was lower search precision, the number of measures located were acceptable. Second, we searched databases associated with clinical and medical research data and thus missed relevant journals whose main focus are religion and spirituality. Here, for example we located two studies investigating the use of the BENEFIT scale and SpNQ, however, several further articles (Büssing and Recchia 2016; Büssing and Koenig 2010; Büssing et al. 2013c) were published in journals not cited by PubMed, EMBASE and PsycINFO. Additionally, several measures although not used 
in clinical settings were evaluated in samples such as stressed soldiers, mothers of sick children and elderly people in care homes whose data would have benefited our review (Büssing and Recchia 2016; Erichsen and Büssing 2013; Büssing et al. 2017). Our scoping review also had several strengths. First, our literature search was focused only on those measures used in clinical settings and thus useful for physicians when trying to determine which instruments to use during clinical assessment. Although, measures validated and applied in psychiatric, social and theological settings may be useful in clinical settings, they were excluded from this review. Second, once measures were accepted, we expanded our protocols to search the name of each measure using "titles and abstracts" to identify and given an indication of validity and reliability, the number of translations to different languages and the number times applied within clinical settings.

\section{Conclusions}

This scoping review provides a current summary on self-reporting and clinician-administered measures used in clinical settings. These measures evaluate several dimensions of spirituality and religiosity that include well-being, beliefs, needs and distress. Importantly, we show a current lack of reliable measures evaluating spiritual needs and distress where outcomes will assist in the spiritual care of patients. Here, our findings suggest that studies are required to develop (a) clinician-administered measures evaluating spiritual needs and distress and (b) further develop self-reporting measures evaluating spiritual needs and distress.

Author Contributions: Philip Austin and Roderick MacLeod conceived and designed the scoping review; Philip Austin and Jessica Macdonald performed the scoping review; Philip Austin and Jessica Macdonald analyzed the data; Philip Austin wrote the paper.

Conflicts of Interest: The authors declare no conflict of interest.

\section{References}

Astrow, Alan B., Rashmi K. Sharma, Yiwu Huang, Yiquing Xu, and Daniel P. Sulmasy. 2012. A Chinese version of the Spiritual Needs Assessment for patients survey instrument. Journal of Palliative Medicine 15: 1297-315. [CrossRef] [PubMed]

Astrow, Alan B., Gary Kwok, Rashmi K. Sharma, and Daniel Sulmasy. 2015. Spiritual needs and patient satisfaction in multi-cultural patient population. Journal of Clinical Oncology 33: e20589.

Austin, Philip D., Roderick Macleod, Philip J. Siddall, Wilf McSherry, and Richard Egan. 2016. The Ability of Hospital Staff to Recognize and Meet Patients' Spiritual Needs: A Pilot Study. Journal for the Study of Spirituality 6: 20-37. [CrossRef]

Austin, Philip, Roderick Macleod, Philip Siddall, Wilf McSherry, and Richard Egan. 2017. Spiritual care training is needed for clinical and non-clinical staff to manage patients' spiritual needs. Journal for the Study of Spirituality 7: 50-63. [CrossRef]

Balboni, Michael J., Adam Sullivan, Adaugo Amobi, Andrea C. Phelps, Daniel P. Gorman, Angelika Zollfrank, John R. Peteet, Holly G. Prigerson, Tyler J. VanderWeele, and Tracy A. Balboni. 2013. Why is spiritual care infrequent at the end of life? Spiritual care perceptions among patients, nurses, and physicians and the role of training. Journal of Clinical Oncology 31: 461-67. [CrossRef]

Baumsteiger, Rachel, and Tiffany Chenneville. 2015. Challenges to the Conceptualization and Measurement of Religiosity and Spirituality in Mental Health Research. Journal of Religion and Health 54: 2344-54. [CrossRef] [PubMed]

Becker, Penny Edgell, and Pawan H. Dhingra. 2001. Religious involvement and volunteering: Implications for civil society. Sociology of Religion 62: 315-35. [CrossRef]

Bekelman, David B., Carla Parry, Farr A. Curlin, Traci E. Yamashita, Diane L. Fairclough, and Frederick S. Wamboldt. 2010. A comparison of two spirituality instruments and their relationship with depression and quality of life in chronic heart failure. Journal of Pain and Symptom Management 39: 515-26. [CrossRef] [PubMed] 
Buck, Harleah G., and Susan C. McMillan. 2012. A psychometric analysis of the spiritual needs inventory in informal caregivers of patients with cancer in hospice home care. Oncology Nursing Forum 39: E332-9. [CrossRef] [PubMed]

Bussing, Arndt, and Harold G. Koenig. 2008. The BENEFIT through spirituality/religiosity scale-A 6-item measure for use in health outcome studies. The International Journal of Psychiatry in Medicine 38: 493-506.

Büssing, Arndt, and Harold G. Koenig. 2010. Spiritual Needs of Patients with Chronic Diseases. Religions 1: 18. [CrossRef]

Büssing, Arndt, and Daniela Rodrigues Recchia. 2016. Spiritual and Non-spiritual Needs Among German Soldiers and Their Relation to Stress Perception, PTDS Symptoms, and Life Satisfaction: Results from a Structural Equation Modeling Approach. Journal of Religion and Health 55: 747-64. [CrossRef] [PubMed]

Büssing, Arndt, Hans J. Balzat, and Peter Heusser. 2010. Spiritual needs of patients with chronic pain diseases and cancer—validation of the spiritual needs questionnaire. European Journal of Medical Research 15: 266-73. [CrossRef]

Bussing, A., Xiao F. Zhai, Wen B. Peng, and Chang Q. Ling. 2013. Psychosocial and spiritual needs of patients with chronic diseases: Validation of the Chinese version of the Spiritual Needs Questionnaire. Journal of Integrative Medicine 11: 106-15. [CrossRef] [PubMed]

Büssing, Arndt, Andreas Günther, Klaus Baumann, Eckhard Frick, and Christoph Jacobs. 2013. Spiritual Dryness as a Measure of a Specific Spiritual Crisis in Catholic Priests: Associations with Symptoms of Burnout and Distress. Evidence-Based Complementary and Alternative Medicine 2013: 10. [CrossRef] [PubMed]

Büssing, Arndt, Annina Janko, Klaus Baumann, Niels Christian Hvidt, and Andreas Kopf. 2013. Spiritual Needs among Patients with Chronic Pain Diseases and Cancer Living in a Secular Society. Pain Medicine 14: 1362-73. [CrossRef] [PubMed]

Büssing, Arndt, Undine Waßermann, Niels Christian Hvidt, Alfred Laengler, and Michael Thiel. 2017. Spiritual needs of mothers with sick new born or premature infants-A cross sectional survey among German mothers. Women and Birth: Journal of the Australian College of Midwives. [CrossRef]

Büssing, Arndt, Daniela R. Recchia, Harold Koenig, Klaus Baumann, and Ecjhard Frick. 2018. Factor Structure of the Spiritual Needs Questionnaire (SpNQ) in Persons with Chronic Diseases, Elderly and Healthy Individuals. Religions 9: 13. [CrossRef]

Cetinkaya, Bengü, Sebahat Dundar, and Arife Azak. 2013. Nurses' perceptions of spirituality and spiritual care. Australian Journal of Advanced Nursing 31: 5-10.

Chiang, Yi-chien, Hsiang-chun Lee, Tsung-lan Chu, Chin-yen Han, and Ya-chu Hsiao. 2017. Psychometric Testing of a Religious Belief Scale. The Journal of Nursing Research: JNR 25: 419-28. [CrossRef] [PubMed]

Colquhoun, Heather L., Danielle Levac, Kelly K. O’Brien, Sharon Straus, Andrea C. Tricco, Laure Perrier, Monika Kastner, and David Moher. 2014. Scoping reviews: Time for clarity in definition, methods, and reporting. Journal of Clinical Epidemiology 67: 1291-94. [CrossRef] [PubMed]

Cotton, Sian, Christina M. Puchalski, Susan N. Sherman, Joseph M. Mrus, Amy H. Peterman, Judith Feinberg, Kenneth I. Pargament, Amy C. Justice, Anthony C. Leonard, and Joel Tsevat. 2006. Spirituality and Religion in Patients with HIV/AIDS. Journal of General Internal Medicine 21: S5-S13. [CrossRef] [PubMed]

Curcio, Cristiane S., Giancarlo Lucchetti, and Alexander Moreira-Almeida. 2015. Validation of the Portuguese version of the Brief Multidimensional Measure of Religiousness/Spirituality (BMMRS-P) in clinical and non-clinical samples. Journal of Religion and Health 54: 435-48. [CrossRef]

Daaleman, Timothy P., and Bruce B. Frey. 2004. The Spirituality Index of Well-Being: A New Instrument for Health-Related Quality-of-Life Research. Annals of Family Medicine 2: 499-503. [CrossRef] [PubMed]

Daaleman, Timothy P., Bruce B. Frey, Dennise Wallace, and Stephanie A. Studenski. 2002. Spirituality Index of Well-Being Scale: Development and testing of a new measure. The Journal of Family Practice 51: 952. [PubMed]

De Araujo Toloi, Diego, Deise Uema, Felipe Matsushita, Paulo Antonio da Silva Andrade, Tiago Pugliese Branco, Fabiana Tomie Becker de Carvalho Chino, Raquel Bezerra Guerra, Túlio Eduardo Flesch Pfiffer, Toshio Chiba, Rodrigo Santa Cruz Guindalini, and et al. 2016. Validation of questionnaire on the Spiritual Needs Assessment for Patients (SNAP) questionnaire in Brazilian Portuguese. Ecancermedicalscience [Internet] 10: 1-694. [CrossRef] [PubMed]

De Araujo Toloi, Diego, Deise Uema, Felipe Matsushita, Paulo Antonio da Silva Andrade, Tiago Pugliese Branco, Fabiana Tomie Becker de Carvalho Chino, Raquel Bezerra Guerra, Túlio Eduardo Flesch Pfiffer, Toshio Chiba, Rodrigo Santa Cruz Guindalini, and et al. 2016b. Validation of questionnaire on the Spiritual Needs 
Assessment for Patients (SNAP) questionnaire in Brazilian Portuguese. Ecancermedicalscience 10: 694. [CrossRef] [PubMed]

Delaney, Colleen. 2005. The Spirituality Scale: Development and psychometric testing of a holistic instrument to assess the human spiritual dimension. Journal of Holistic Nursing 23: 145-67, discussion 68-71. [CrossRef]

Delaney, Colleen, Cynthia Barrere, and Mary Helming. 2011. The influence of a spirituality-based intervention on quality of life, depression, and anxiety in community-dwelling adults with cardiovascular disease: A pilot study. Journal of Holistic Nursing: Official Journal of the American Holistic Nurses' Association 29: 21-32. [CrossRef] [PubMed]

Erichsen, Nora-Beata, and Arndt Büssing. 2013. Spiritual Needs of Elderly Living in Residential/Nursing Homes. Evidence-Based Complementary and Alternative Medicine 2013: 10. [CrossRef] [PubMed]

Exline, Julie J., Kenneth I. Pargament, Joshua B. Grubbs, and Ann Marie Yali. 2014. The Religious and Spiritual Struggles Scale: Development and initial validation. Psychology of Religion and Spirituality 6: $208-22$. [CrossRef]

Fallahi Khoshknab, Masoud, Monir Mazaheri, Sadat S.B. Maddah, and Mehdi Rahgozar. 2010. Validation and reliability test of Persian version of The Spirituality and Spiritual Care Rating Scale (SSCRS). Journal of Clinical Nursing 19: 2939-41. [CrossRef] [PubMed]

Fernander, Anita, John F. Wilson, Michele Staton, and Carl Leukefeld. 2004. An exploratory examination of the Spiritual Well-Being Scale among incarcerated black and white male drug users. International Journal of Offender Therapy and Comparative Criminology 48: 403-13. [CrossRef] [PubMed]

Fischbeck, Sabine, Bernd O. Maier, Ulrike Reinholz, Cornelia Nehring, Rainer Schwab, and Manfred E. Beutel. 2013. Assessing somatic, psychosocial, and spiritual distress of patients with advanced cancer: Development of the Advanced Cancer Patients' Distress Scale. The American Journal of Hospice \& Palliative Care 30: 339-46.

Genia, Vickly. 2001. Evaluation of the Spiritual Well-Being Scale in a Sample of College Students. The International Journal for the Psychology of Religion 11: 25-33.

Gherghina, Viorel, I. Cindea, R. Popescu, and A. Balcan. 2014. Spiritual distress assessment tool a valid instrument for elderly patients in the perioperative period: 18AP3-7. European Journal of Anaesthesiology 31: 267. [CrossRef]

Ghodsbin, Fariba, Marzieh Safaei, Iahanbin Jahanbin, Mohammed A. Ostovan, and Sareh Keshvarzi. 2015. The effect of positive thinking training on the level of spiritual well-being among the patients with coronary artery diseases referred to Imam Reza specialty and subspecialty clinic in Shiraz, Iran: A randomized controlled clinical trial. ARYA Atherosclerosis 11: 341-48. [PubMed]

Hatch, Robert L., Mary A. Burg, Debra S. Naberhaus, and Linda K. Hellmich. 1998. The Spiritual Involvement and Beliefs Scale. Development and testing of a new instrument. The Journal of Family Practice 46: 476-86. [PubMed]

Hermann, Carla. 2006. Development and testing of the spiritual needs inventory for patients near the end of life. Oncology Nursing Forum 33: 737-44. [CrossRef] [PubMed]

Hill, Peter C., and Kenneth I. Pargament. 2003. Advances in the conceptualization and measurement of religion and spirituality. Implications for physical and mental health research. The American Psychologist 58: 64-74. [CrossRef] [PubMed]

Hood, Ralph W., and Bernard Spilka. 2003. The Psychology of Religion: An Empirical Approach, 3rd ed. New York: Guilford Press.

Hyman, Corine, and Paul J. Handal. 2006. Definitions and Evaluation of Religion and Spirituality Items by Religious Professionals: A Pilot Study. Journal of Religion and Health 45: 264-82. [CrossRef]

Ironson, Gail, George F. Solomon, Elizabeth G. Balbin, Conall O'Cleirigh, Annie George, Mahendra Kumar, David Larson, and Teresa E. Woods. 2002. The Ironson-woods Spirituality/Religiousness Index is associated with long survival, health behaviors, less distress, and low cortisol in people with HIV / AIDS. Annals of Behavioral Medicine: A Publication of the Society of Behavioral Medicine 24: 34-48. [CrossRef]

Johnstone, Brick, Dong P. Yoon, Kelly L. Franklin, Laura Schopp, and Joseph Hinkebein. 2009. Re-conceptualizing the factor structure of the brief multidimensional measure of religiousness/spirituality. Journal of Religion and Health 48: 146-63. [CrossRef]

Kimura, Miako, Acacia L. de Oliveira, Lina S. Mishima, and Lynn G. Underwood. 2012. Cultural adaptation and validation of the Underwood's Daily Spiritual Experience Scale-Brazilian version. Revista da Escola de Enfermagem da U S P 46: 99-106. [CrossRef] [PubMed] 
Koenig, Harold G. 2009. Research on religion, spirituality, and mental health: A review. Canadian Journal of Psychiatry Revue Canadienne de Psychiatrie 54: 283-91. [CrossRef] [PubMed]

Koenig, Harold G. 2012. Religion, Spirituality, and Health: The Research and Clinical Implications. ISRN Psychiatry 2012: 33. [CrossRef] [PubMed]

Koenig, Harold G., Nathan A. Boucher, and Michelle J. Pearce. 2017. Rationale for Spiritually Oriented Cognitive Processing Therapy for Moral Injury in Active Duty Military and Veterans with Posttraumatic Stress Disorder. The Journal of Nervous and Mental Disease 205: 147-53. [PubMed]

Kouloulias, Vassilis, John Kokakis, Nikolaos Kelekis, and John Kouvaris. 2017. A New Questionnaire (QRFPC25) Regarding the Religiosity and Spirituality in People with Life-Threatening Disease: Reliability and Validity in a Population of Cancer Patients Undergoing Radiotherapy. Journal of Religion and Health 56: 1137-54. [CrossRef]

Kreitzer, Mary J., Cynthia R. Gross, On A. Waleekhachonloet, Maryanne Reilly-Spong, and Marcia Byrd. 2009. The brief serenity scale: A psychometric analysis of a measure of spirituality and well-being. Journal of Holistic Nursing 27: 7-16. [CrossRef]

Ku, Ya L., Shih M. Kuo, and Ching Y. Yao. 2010. Establishing the validity of a spiritual distress scale for cancer patients hospitalized in southern Taiwan. International Journal of Palliative Nursing 16: 134-38. [CrossRef] [PubMed]

Lucchetti, Giancarlo, Alessandra Lamas Granero Lucchetti, and Homero Vallada. 2013. Measuring spirituality and religiosity in clinical research: A systematic review of instruments available in the Portuguese language. Sao Paulo Medical Journal = Revista paulista de medicina 131: 112-22. [CrossRef] [PubMed]

MacLeod, Rod, Donna M. Wilson, Jackie Crandall, and Phil Austin. 2017. Death Anxiety among New Zealanders: The Predictive Roles of Religion, Spirituality, and Family Connection. Omega. [CrossRef] [PubMed]

Mateen, Farrah J., Jiwon Oh, Ana I. Tergas, Neil Bhayani, and Biren Bharat Kamdar. 2013. Titles versus titles and abstracts for initial screening of articles for systematic reviews. Clinical Epidemiology 5: 89-95. [CrossRef] [PubMed]

McBride, J.L., G. Arthur, R. Brooks, and L. Pilkington. 1998a. The relationship between a patient's spirituality and health experiences. Family Medicine 30: 122-6.

McBride, J.L., L. Pilkington, and G. Arthur. 1998b. Development of brief pictorial instruments for assessing spirituality in primary care. The Journal of Ambulatory care Management 21: 53-61. [CrossRef]

McSherry, Wilfred, Peter Draper, and Don Kendrick. 2002. The construct validity of a rating scale designed to assess spirituality and spiritual care. International Journal of Nursing Studies 39: 723-34. [CrossRef]

Mistretta, Erin G., Danetta Sloan, Karlynn BrintzenhofeSzoc, Kathleen M. Weber, and Ann Berger. 2017. Testing domains of the healing experiences in all life stressors questionnaire in a cohort of HIV-infected and HIV-uninfected Chicago women. Psychology Research and Behavior Management 10: 201-8. [CrossRef] [PubMed]

Moeini, Babak, Hadi Zamanian, Zahra Taheri-Kharameh, Tehereh Ramezani, Mohamadhasan Saati-Asr, Mohamadhasan Hajrahimian, and Mohammadali Amini-TehraniMscb. 2018. Translation and Psychometric Testing of the Persian Version of the Spiritual Needs Questionnaire Among Elders with Chronic Diseases. Journal of Pain and Symptom Management 55: 94-100. [CrossRef] [PubMed]

Monod, Stefanie M., Etienne Rochat, Christophe J. Bula, Guy Jobin, Estelle Martin, and Brenda Spencer. 2010. The spiritual distress assessment tool: An instrument to assess spiritual distress in hospitalised elderly persons. BMC Geriatrics 10: 88. [CrossRef] [PubMed]

Monod, Stefanie, Mark Brennan, Etienne Rochat, Estelle Martin, Stephane Rochat, and Chrisotphe J. Büla. 2011. Instruments Measuring Spirituality in Clinical Research: A Systematic Review. Journal of General Internal Medicine 26: 1345-57. [CrossRef] [PubMed]

Monod, Stefanie, Estelle Martin, Brenda Spencer, Etienne Rochat, and Christophe Bula. 2012. Validation of the Spiritual Distress Assessment Tool in older hospitalized patients. BMC Geriatrics 12: 13. [CrossRef] [PubMed]

Monod, Stepfanie, Estelle Martin, Brenda Spencer, Etienne Rochat, and Christophe Büla. 2012. Validation of the spiritual distress assessment tool in older hospitalized patients. BMC Geriatrics 12: 13. [CrossRef] [PubMed]

Munoz, Alexis R., John M. Salsman, Kevin D. Stein, and David Cella. 2015. Reference Values of the Functional Assessment of Chronic Illness Therapy—Spiritual Well-Being (FACIT-Sp-12): A Report from the American Cancer Society's Studies of Cancer Survivors. Cancer 121: 1838-44. [CrossRef] [PubMed] 
Mystakidou, Kyriaki, Eleni Tsilika, Efi Parpa, M. Smyrnioti, and Lambros Vlahos. 2006. Assessing spirituality and religiousness in advanced cancer patients. The American Journal of Hospice \& Palliative Care 23: 457-63.

Mystakidou, Kyriaki, Eleni Tsilika, Efi Parpa, Maria Pathiaki, Elisabeth Patiraki, Antonis Galanos, and Lambros Vlahos. 2007. Exploring the relationships between depression, hopelessness, cognitive status, pain, and spirituality in patients with advanced cancer. Archives of Psychiatric Nursing 21: 150-61. [CrossRef] [PubMed]

Mystakidou, Kyriaki, Eleni Tsilika, Efi Parpa, Ioanna Hatzipli, Marilena Smyrnioti, Antonis Galanos, and Lambros Vlahos. 2008. Demographic and clinical predictors of spirituality in advanced cancer patients: a randomized control study. Journal of Clinical Nursing 17: 1779-85. [CrossRef] [PubMed]

Mystakidou, Kyriaki, Eleni Tsilika, Efi Prapa, Marilena Smyrnioti, Anna Pagoropoulou, and Lambros Vlahos. 2008. Predictors of spirituality at the end of life. Canadian Family Physician Medecin de Famille Canadien 54: 1720-21.e5. [PubMed]

Oji, V.U., L.C. Hung, R. Abbasgholizadeh, Hamilton F. Terrell, E.J. Essien, and E. Nwulia. 2017. Spiritual care may impact mental health and medication adherence in HIV+ populations. HIV/AIDS (Auckland, NZ) 9: 101-109. [CrossRef] [PubMed]

Peterman, Amy H., George Fitchett, Marianne J. Brady, Lesbia Hernandez, and David Cella. 2002. Measuring spiritual well-being in people with cancer: The functional assessment of chronic illness therapy-Spiritual well-being scale (FACIT-Sp). Annals of Behavioral Medicine 24: 49-58. [CrossRef] [PubMed]

Puchalski, Christina M. 2001. The role of spirituality in health care. Proceedings (Baylor University Medical Center) 14: 352-57. [CrossRef]

Puchalski, Christina, Betty Ferrell, Rose Virani, Shirley Otis-Green, Pamela Baird, Janet Bull, Harvey Chochinov, George Handzo, Holly Nelson-Becker, Maryjo Prince-Paul, and et al. 2009. Improving the Quality of Spiritual Care as a Dimension of Palliative Care: The Report of the Consensus Conference. Journal of Palliative Medicine 12: 885-904. [CrossRef] [PubMed]

Rasinski, Kenneth A., Y.G. Kalad, J.D. Yoon, and F.A. Curlin. 2011. An assessment of US physicians' training in religion, spirituality, and medicine. Medical Teacher 33: 944-45. [CrossRef] [PubMed]

Rusa, Suzana Gabriela Rusa, Gabriele Ibanhes Peripato, Sofia Cristina Iost Pavarini, Keika Inouye, Marisa Silvana Zazzetta, and Fabiana de Souza Orlandi. 2014. Quality of life/spirituality, religion and personal beliefs of adult and elderly chronic kidney patients under hemodialysis. Revista Latino-Americana de Enfermagem 22: 911-17. [CrossRef] [PubMed]

Sharma, Rashmi K., Alan B. Astrow, Kenneth Texeira, and Daniel P. Sulmasy. 2012. The Spiritual Needs Assessment for Patients (SNAP): development and validation of a comprehensive instrument to assess unmet spiritual needs. Journal of Pain and Symptom Management 44: 44-51. [CrossRef] [PubMed]

Simao, Talita P., Erika de Cássia Lopes Chaves, Emília Campos de Carvalho, Denismar Alves Nogueira, Camila Csizmar Carvalho, Ya-Li Ku, and Denise Hollanda Iunes. 2016. Cultural adaptation and analysis of the psychometric properties of the Brazilian version of the Spiritual Distress Scale. Journal of Clinical Nursing 25: 231-39. [CrossRef] [PubMed]

Steinhauser, Karen E., Stewart C. Alexander, Ira R. Byock, Linda K. George, Maren K. Olsen, and James A. Tulsky. 2008. Do preparation and life completion discussions improve functioning and quality of life in seriously ill patients? Pilot randomized control trial. Journal of Palliative Medicine 11: 1234-40. [CrossRef] [PubMed]

Van Leeuwen, Rene, Lucas J. Tiesinga, Berrie Middel, Doeke Post, and Henk Jochemsen. 2009. The validity and reliability of an instrument to assess nursing competencies in spiritual care. Journal of Clinical Nursing 18: 2857-69. [CrossRef] [PubMed]

VandeCreek, Larry, Susan Ayres, and Meredith Bassham. 1995. Using INSPIRIT to conduct spiritual assessments. Journal of Pastoral Care 49: 83-89. [CrossRef] [PubMed]

Vivat, Bella, Teresa E. Young, J. Winstanley, J.I. Arraras, K. Black, F. Boyle, A. Bredart, A. Costantini, J. Guo, M.E. Irarrazaval, and et al. 2017. The international phase 4 validation study of the EORTC QLQ-SWB32: A stand-alone measure of spiritual well-being for people receiving palliative care for cancer. European Journal of Cancer Care (England) 26. [CrossRef] [PubMed]

WHOQOL SRPB Group. 2006. A cross-cultural study of spirituality, religion, and personal beliefs as components of quality of life. Social Science E Medicine 62: 1486-97.

$\mathrm{Wu}$, Li-Fen, and Lih-Ying Lin. 2011. Exploration of clinical nurses' perceptions of spirituality and spiritual care. The Journal of Nursing Research: JNR 19: 250-6. [CrossRef] [PubMed] 
Wu, Li-Fen, Shu-Hui Yang, and Malcolm Koo. 2017. Psychometric properties of the Chinese version of Spiritual Index of Well-Being in elderly Taiwanese. BMC Geriatrics 17: 3. [CrossRef] [PubMed]

Xue, S., S. Arya, A. Embuldeniya, H. Narammalage, Tricia da Silva, Shehan Williams, and A. Ravindran. 2016. Perceived functional impairment and spirituality/religiosity as predictors of depression in a Sri Lankan spinal cord injury patient population. Spinal Cord 54: 1158-63. [CrossRef] [PubMed]

Zimmer, Zachary, Carol Jagger, Chi-Tsun Chiu, Mary Beth Ofstedal, Florencia Rojo, and Yasuhiko Saito. 2016. Spirituality, religiosity, aging and health in global perspective: A review. SSM-Population Health 2: 373-81. [CrossRef] [PubMed]

(C) 2018 by the authors. Licensee MDPI, Basel, Switzerland. This article is an open access article distributed under the terms and conditions of the Creative Commons Attribution (CC BY) license (http://creativecommons.org/licenses/by/4.0/). 